\title{
GEOSPATIAL FORECAST MODEL FOR TSETSE-TRANSMITTED ANIMAL TRYPANOSOMOSIS IN ETHIOPIA
}

\author{
Getachew Abebe ${ }^{1}$, John B. Malone ${ }^{2}$ and Alexander R. Thompson ${ }^{2}$ \\ Faculty of Veterinary Medicine, Addis Ababa University, PO Box 34 \\ Debre Zeit, Ethiopia. E-mail: gabebe@med.aau.edu.et \\ Department of Pathobiological Sciences, School of Veterinary Medicine \\ Louisiana State University, Baton Rouge, LA 70803, USA
}

\begin{abstract}
The aims of this study were to develop a geographic information systems (GIS) forecast and risk assessment model for cyclically transmitted trypanosomosis in Ethiopia by matching features in the environment to available information on the preferences and limits of tolerance of the parasite and its vector, and validate and further develop the GIS model using data from current and historical prevalence survey data and habitat microenvironment studies from trypanosomosis endemic areas. Results indicate that GIS model developed for parasitic diseases based on growing degree day (GDD) concept can be applied to tsetse-transmitted trypanosomosis. GIS for animal trypanosomosis was created using Food and Agriculture Organization - Crop Production System Zones (FAO-CPSZ) database and Normalized Difference Vegetation Index (NDVI) and maximum temperature (Tmax) from the Global Land $1 \mathrm{~km}$ dataset. The two datasets used to determine the risk of tsetse flies and consequently animal trypanosomosis in Ethiopia indicated the magnitude of the disease and possible expansion of the "fly belt" in the future. The GIS model indicated the distribution and importance of tsetse-transmitted trypanosomosis in Ethiopia. Spatial and statistical analysis verified the use of GDD concept and climate forecast system that was developed to determine the suitability of a given environment for the proliferation of a biotype, in this case tsetse and trypanosomes. Results presented here indicate the importance of GDD and the two climatic variables (NDVI and Tmax) in the development of forecast model for tsetse-transmitted trypanosomosis in Ethiopia.
\end{abstract}

\section{Key words/phrases: Ethiopia, GIS, NDVI, Tmax, trypanosomosis}

\section{INTRODUCTION}

Ethiopia, with its great variation in climate and topography, possesses the largest cattle population in Africa. However, livestock productivity remains marginal due to prevalent diseases, malnutrition and management constraints. Tsetse-transmitted trypanosomosis, locally referred as 'Ghendi' caused principally by Trypanosoma congolense, $T$. vivax and T. brucei, is one of the major cattle health constraints in the country (Zeleke Dagnachew et al., 1985; Rowlands, et al., 1995; Getachew Abebe and Yilma Jobre, 1996). The early works of Langridge (1976) indicated that tsetse flies infested about $98,000 \mathrm{~km}^{2}$ of potentially fertile land in the southwestern part of Ethiopia denying efficient agricultural activity in the region. However, precise information on the distribution and abundance of these vector flies as well as the disease are scanty. The pattern of disease transmission by tsetse flies, on the other hand, varies markedly from region to region, depending on climate and biogeography, and broad ecological categories have been widely used to describe variations in the observed epidemiological features in an area (Ephraim Mamo, 1993; Getachew Abebe and Yilma Jobre, 1996). Careful definition of environmental factors that govern the vector ecology and disease transmission patterns are essential steps towards the development and institution of a sound trypanosomosis control scheme both at a national and regional level.

Geographic information systems (GIS) provide a way to use computers to create, archive and analyze traditional map data on epidemiology of diseases and to combine these with global environmental data derived from sensors on board earth-observing satellites. A GIS is created by linking standard computer database 'attributes' to map features represented as digital vector 
(polygons, points, lines) or 'raster' image. Using a new generation of commercially available digital geographic databases and hand held geographic positioning systems (GPS) precise point location and maps can be created for disease applications.

Crop models are well known that describe the suitability of different environments for cultivation and recommended times for planting, fertilizer and pest control (Van Velthuizen et al., 1995). It is proposed that similar methods can be developed, with GIS agroclimatic databases and satellite sensor technology, to describe the distribution range and suitability of different areas for propagation and transmission of disease, and that this information can be used to design control programs and optimize interventions.

Literature reports on GIS medical and veterinary applications include malaria (Beck et al., 1994; 2000; Bergquist, 2001), rift valley fever (Linthicum et al., 1987), filariasis (Thompson et al., 1996), African trypanosomosis (Rogers and Randolph, 1993; Rogers, 2000; Hendrickx et al., 2001), theileriosis (Lessard et al., 1990), Onchocerciasis (Richards, 1993), Leishmaniasis (Cross et al., 1996), Amblyomma variegatum (Hugh-Jones et al., 1992), lyme disease (Kitron et al., 1992); Fascioliasis (Zukowski et al., 1991; Malone et al., 1992; Malone and Zukowski, 1992; Malone et al., 1998; Yilma Jobre and Malone, 1998), and Schistosomiasis (Cross and Bailey, 1984; Malone et al., 1997; Malone et al., 2001).

The aims of this study were to develop a GIS forecast and risk assessment model for cyclically transmitted trypanosomosis in Ethiopia by matching features in the environment to available information on the preferences and limits of tolerance of the parasite and its vector, and validate and further develop the GIS model using data from current and historical prevalence survey data and habitat microenvironment studies from trypanosomosis endemic areas.

\section{MATERIALS AND METHODS}

\section{GIS construction}

The GIS databases were developed using ArcView 3.2 GIS (ESRI, Redlands, CA) and ERDAS imagine 8.3.1 (ERDAS, Atlanta, GA) softwares. The Food and Agriculture (FAO) Crop production System Zone
(CPSZ) database was originally developed for predicting a relative ecological suitability of an area for various crops (Van Velthuizen et al., 1995). According to agro-climatic environmental classes CPSZ boundary files were defined by classifying administrative units, or sub-units of administrative units if sharp ecological demarcations occur. Selected environmental features for 460 CPSZ in Ethiopia were extracted from CPSZ database and imported into ArcView 3.2 (ESRI, Redlands, Ca) as shape files for comparison to a compilation of animal trypanosomosis survey data available at the Faculty of Veterinary Medicine, Addis Ababa University from 1985 (Getachew Abebe and Yilma Jobre, 1996), National Tsetse and Trypanosomiasis Investigation and Control Centre (Zeleke Dagnachew et al., 1985; NTTICC, 2000) and Langridge's study report (Langridge, 1976). Prevalence data for the analysis was limited to 65 sites for which accurate latitude-longitude map coordinates were available. Global 1-km data was downloaded, imported as image file and calibrated to NDVI and Tmax values as described previously in studies on schistosomiasis (Malone et al., 2001). Briefly the Global 1-km format for NDVI is scaled to positive values of $0-200$ rather than accepted -1 to +1 NDVI range. Tmax data calibration yielded midday earth surface temperature values. Regional scale AVHRR data and other data layers included in the GIS were transformed to geographic, latitudelongitude, decimal degree format using the ESRI Digital Chart of the World (DCW) as a base map standard for GIS construction.

\section{Forecast index based on Growing Degree Days (GDD)}

The climate based parasite forecast system developed for fasciolosis by Yilma Jobre and Malone (1998) and Malone et al. (1998) was adapted to further develop a GIS risk assessment model for tsetse-borne trypanosomosis for Ethiopia. Using growing degree day (GDD) value requirements for life cycle completion on tsetse fly species (G. morsitans submorsitans and G. tachinoides) and a water budget analysis using the Penman method for calculating potential evapotranspiration (PET), monthly forecast indices were 
calculated for major cyclically transmitted Trypanosoma species, in this case $T$. congolense. Annual cumulative index values for specific endemic sites was then stratified and designated as ' 0 ' or no risk area $\leq 0$ index value; ' 1 ' or 'marginal' 1-439 index value; ' 2 ' or 'low' 440-1440 index value and ' 3 ' high risk' $\geq 1441$ index value. Annual cumulative index values (risk index for GDD) ranged from 0-2951.2. The base temperature was the temperature measurement $\left(17^{\circ} \mathrm{C}\right)$ below which no development of tsetse's puparium stage in the environment (Seifert, 1996). GDD is defined as the number of degrees above $17^{\circ} \mathrm{C}$ average annual mean temperature from the CPSZ database.

\section{Forecast index based on Global 1-km composite data}

Evaluation was done to determine global 1-km NDVI and Tmax values consistent with known trypanosomosis areas using scatter diagrams prepared by plotting global 1-km NDVI and Tmax annual composite values, extracted from $10 \mathrm{~km}$ buffer areas centered on prevalence data points, against the infection prevalence survey data for the 65 sites (veterinary clinics). On average veterinary clinics in Ethiopia offer animal health services to a minimum area of $10 \mathrm{~km}$ diameter.

\section{Validation of forecast models}

Trypanosomosis infection prevalence and tsetse abundance database for 460 CPSZ homogenous agroclimatic map units in Ethiopia (IGADD-FAO, 1995) was developed using data obtained from the Faculty of Veterinary Medicine, Addis Ababa University (Getachew Abebe and Yilma Jobre, 1996), National Tsetse and Trypanosomosis Investigation and Control Centre (Zeleke Dagnachew et al., 1985; NTTICC, 2000) and Langridge's survey report (Langridge, 1976). Model validation was carried out by computer based statistical computations employing linear regression (Bruning and Kintz, 1977) to assess the relationship of the known disease and fly distribution with selected physical environmental determinates from the CPSZ database matrix. The latter included climate data (annual rainfall, average annual mean temperature, potential evapotranspiration), altitude and average annual mean normalized difference vegetation index (NDVI).

\section{RESULTS}

\section{Forecast based on GDD}

Varying degrees of tsetse risk occur in all areas of Ethiopia except the central highlands and the northeast and southeast arid areas of the country. The highest risk areas were localized in the western zones associated with the river valleys of Blue Nile, Didessa, Baro, Akobo, Gojeb, Ghibe and Omo. The risk area extended from the southern part of the Rift valley, around the southwestern corner of the country and along the western lowlands and escarpments to the Blue Nile. The risk area further extends north from the Blue Nile to Tekeze River along the Sudan border. In the east the risk area spreads to the north along with the eastern escarpment and Awash River through the northern part of the Rift Valley of Ethiopia. Foci of risk areas were observed along the Wabi-Shebele and Genale Rivers flowing towards Somalia. Varying degrees of tsetse risk areas were found in five of the nine regional states namely, Amhara, Benshangul, Gambella, Oromiya, Southern Nation, Nationalities and People Region. According to the risk model, the eastern lowlands (Afar and Ogaden) and the central highlands of Ethiopia were free from tsetse-transmitted trypanosomosis.

\section{Forecast based on Global 1-km composite data}

To develop optimum criteria ranges for the NDVI and Tmax values for $10 \mathrm{~km}$ buffers, data collection sites were extracted from the combined three-year composite map. Query best-fit results were 135155 for NDVI and $17-27^{\circ} \mathrm{C}$ for Tmax (Fig. 1a, b and Fig. $2 \mathrm{a}, \mathrm{b}$ ). Evaluation on global 1-km NDVI and Tmax values revealed that tsetse infested areas were in best fit with $T$. congolense endemic areas as well as "fly belts" of Ethiopia. 

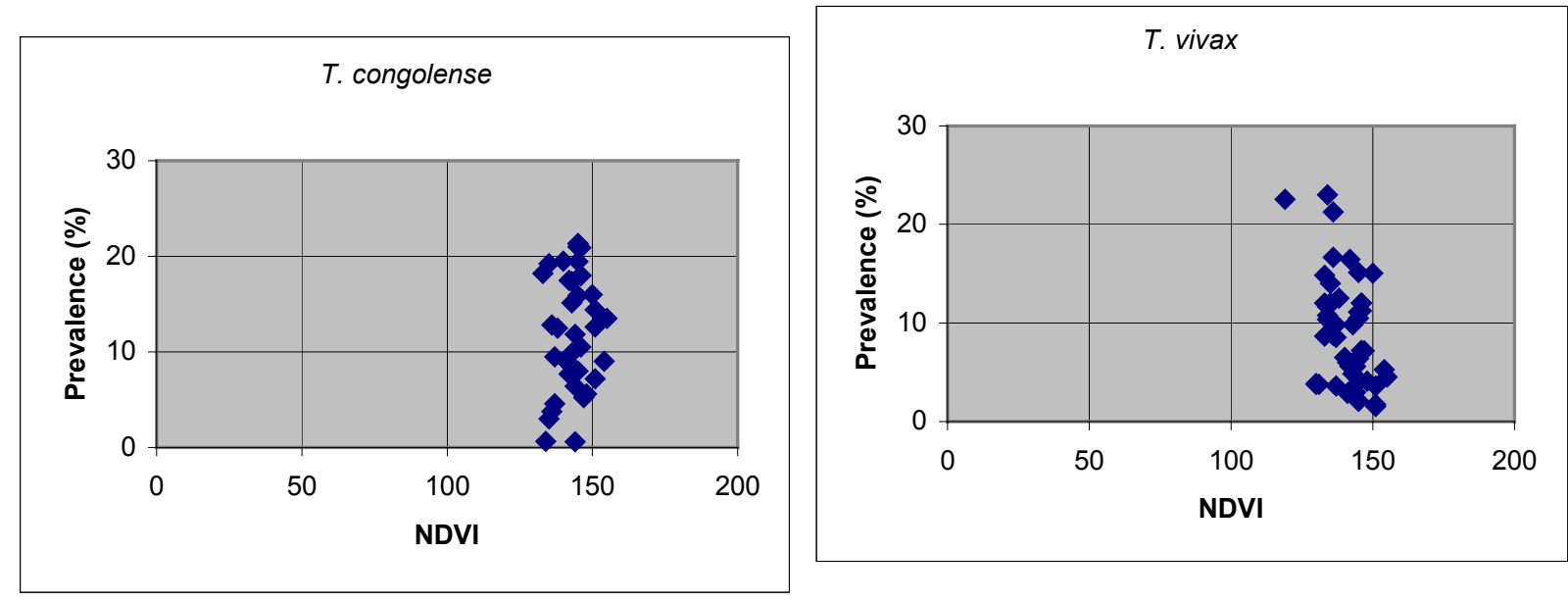

Fig. 1a and b. Scatter diagrams of T. congolense (a) and T. vivax (b) prevalence rate as compared to the values extracted from 1992-1995 composite NDVI from $10 \mathrm{~km}$ diameter areas centered on prevalence survey sites.
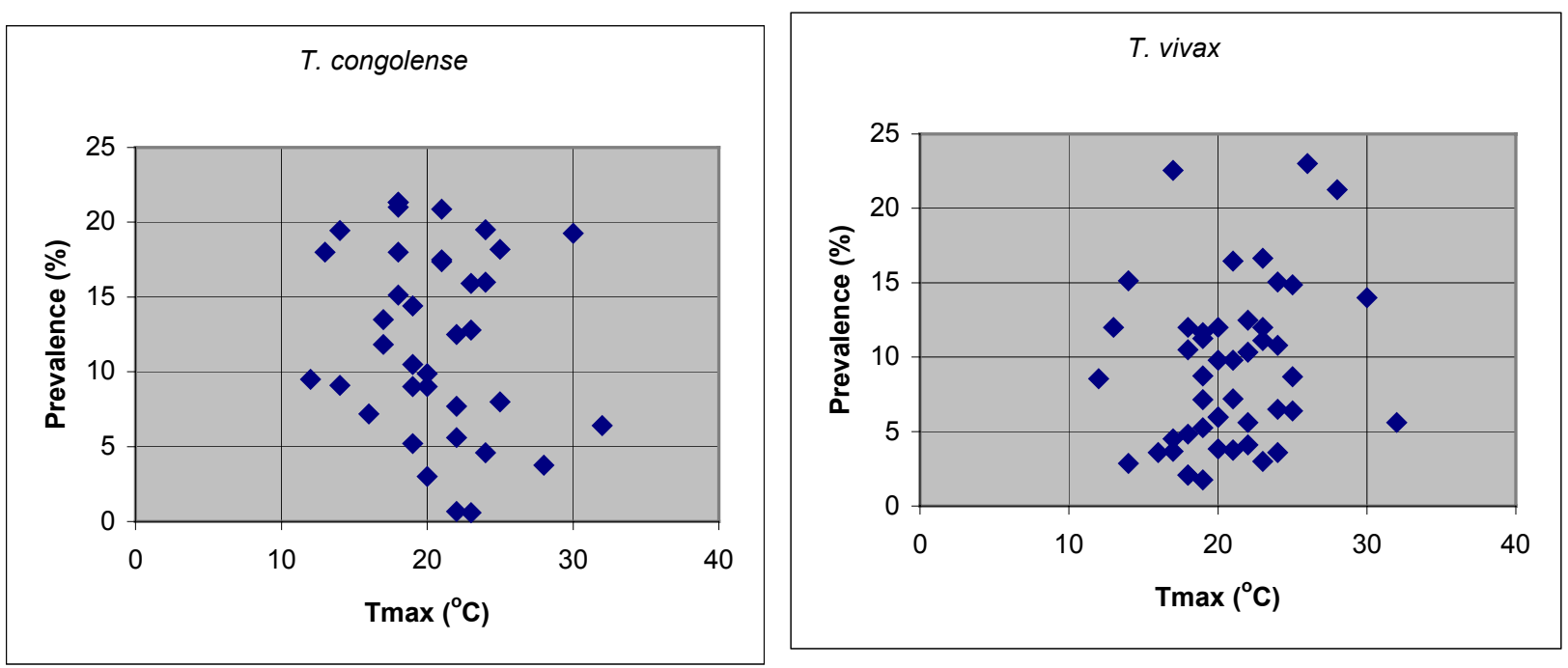

Fig $2 \mathrm{a}$ and $\mathbf{b}$. Scatter diagrams of $T$. congolense (a) and $T$. vivax (b) prevalence rate as compared to the values extracted from 1992-1995 composite Tmax from $10 \mathrm{~km}$ diameter areas centered on prevalence survey sites.

Comparison of the forecast models with known tsetse infested areas

The two forecast models matched with the most authoritative work of Langridge (1976) who surveyed some $213,000 \mathrm{~km}^{2}$ and concluded that some $98,000 \mathrm{~km}^{2}$ were infested (Fig. $3 \mathrm{a}$ and b). All the areas classified by Langridge as high and low risk were within the risk area model of the work reported here. In addition, the prevalence data on tsetse transmitted trypanosomes indicated that with the exception of few foci in the north and central highlands escarpments, tsetse transmitted trypanosomes in particular T. congloense infection was confined to the known "fly belt" of Ethiopia. Analysis revealed a spatial correlation between $T$. congolense $>5 \%$ prevalence and annual forecast index (Fig.1b and Fig. 4a). Nevertheless, there were a number of $T$. congolense prevalence sites on the highlands, just at the margin of the forecast area. These areas were very close to tsetse-infested area and most of the animals from the close by tsetse infested area travel to the nearest clinic on the highlands. T. vivax, one of the most important cattle trypanosomosis next to $T$. congolense was found both in the tsetse infested (Fig. 4b) and tsetse free area. 


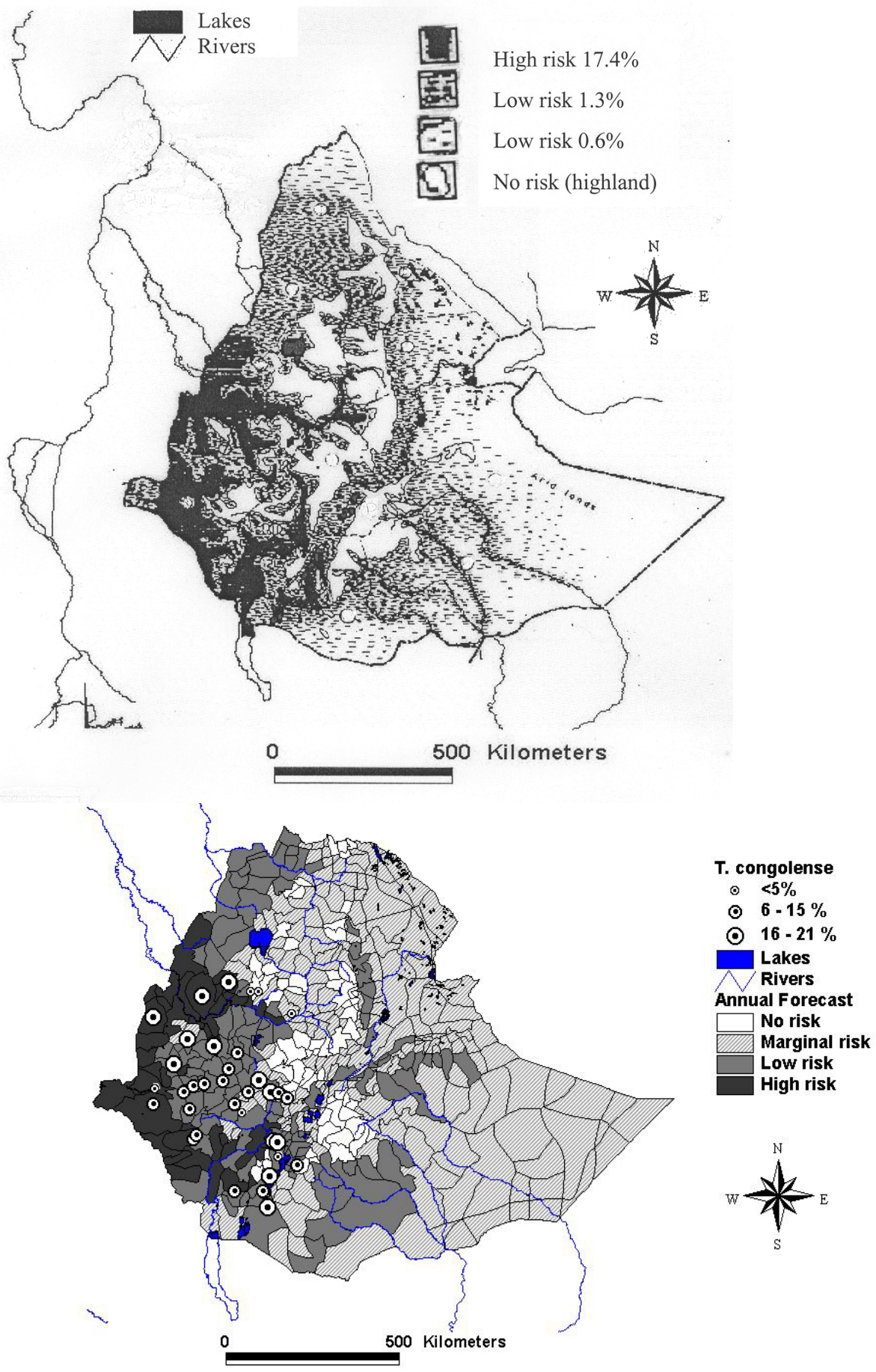

Fig. 3a and b. Langridge's map of tsetse distribution in Ethiopia (a) and GIS map of tsetse and trypanosomosis potential distribution and abundance gradients for Ethiopia with known T. congolense prevalence sites (b).

\section{DISCUSSION}

Results indicate that GIS model developed for parasitic diseases based on GDD concept can be applied to tsetse-transmitted trypanosomosis (Fig. 3b). GIS for animal trypanosomosis was created using FAO-CPSZ database and NDVI and Tmax from the Global Land $1 \mathrm{~km}$ dataset. The two datasets used to determine the risk of tsetse flies and consequently animal trypanosomosis in Ethiopia indicated the magnitude of the disease and possible expansion of the "fly belt" in the future. The GIS model indicated the distribution and importance of tsetse-transmitted trypanosomosis in Ethiopia. Spatial and statistical analysis verified the use of GDD concept and climate forecast system that was developed to determine the suitability of a given environment for the proliferation of a 
biotype, in this case tsetse and trypanosomes. Like other insects, tsetse fly requires specific climate and topography environments for the completion of its life cycle as well as survival. As a result tsetse flies are prone to environmental changes (temperature, moisture, vegetation, altitude, etc). According to Langridge (1976), the tsetse flies in Ethiopia are confined to the southern and western regions between longitude $33^{\circ}$ and $38^{\circ} \mathrm{E}$ and latitude $5^{\circ}$ and $12^{\circ} \mathrm{N}$. They infest areas which together amount to 97,855 square $\mathrm{km}$. Tsetse infested areas lie in the lowlands and also in the river valleys of Blue Nile, Baro, Akobo and Omo. The infested area extends from the southern part of the Rift Valley, around the south-western corner of the country and along the western lowlands and escarpments to the Blue Nile. Restricting a further eastward spread is the cold limit imposed by highlands that rise to the height above which tsetse cannot survive, or the semi-desert condition along the southern border east of the Rift Valley. Langridge (Fig. 3a) was, however, suspicious of the spread of tsetse flies northwards from the Blue Nile to Tekeze River. This possibility is clearly indicated by the forecast model, reported here. Elsewhere there have been advances of tsetse, including extension of the upper altitude limit of the fly from about $1,600 \mathrm{~m}$ to $2,000 \mathrm{~m}$ in certain areas, although it is unclear whether flies caught at the highest altitudes are representative of a self-sustaining stable population, that can persist in these areas. Tsetse fronts in many places are unstable and tsetse-animal interface is constantly moving (NTTICC, 2000). Consequently new areas are being invaded and settled communities are being continually evicted by the advancing tsetse. Such hot spots include the areas in Upper Didessa Valley, the northern and northeastern edges of Lake Abaya in the Rift Valley and, the upper reaches of the Omo-Ghibe and its tributaries.
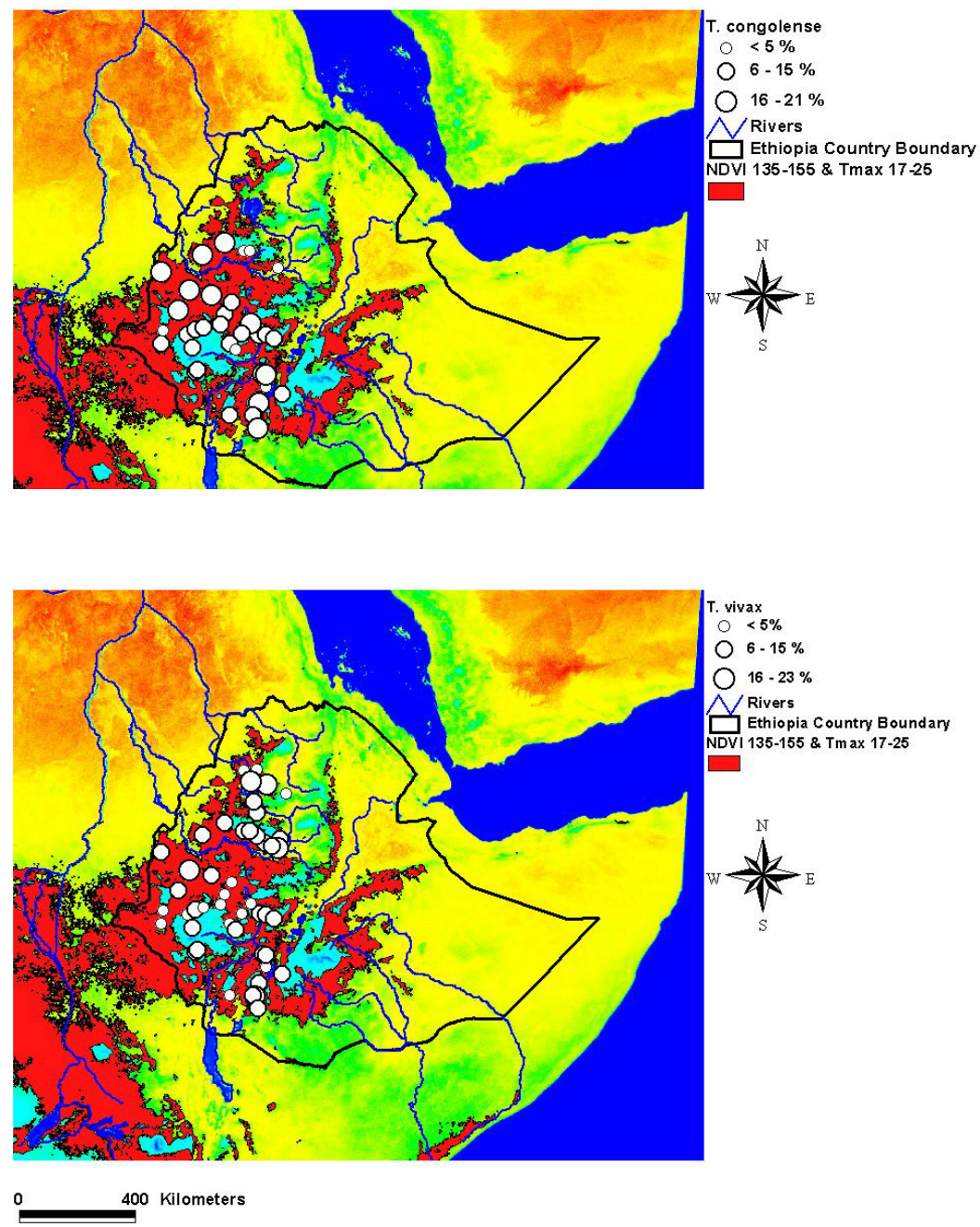

Fig. 4a and b. GIS annual composite model query that met criteria for both NDVI (135-155) and Tmax (17-25) for T. conglolense (a) and T. vivax (b). The area in black represents the best fit for tsetse-transmitted trypanosomes in Ethiopia. 
Five species of Glossina (G. morsitans submorsitans, G. pallidipes, G. tachinoides, G. fuscipes fuscipes and G. longipennis) have been recorded from Ethiopia, but only four are widespread and cause significant economic importance. These are Glossina morsitans submorsitans and G. tachinoides, which have a west to east distribution across Africa south of the Sahara desert, and G. pallidipes and G. fuscipes, which often occur together in East Africa, although the former extends far to the south where as the latter has an essentially central African distribution (Langridge, 1976; NTTICC, 2000).

$T$. congolense and T. vivax are the most prevalent trypanosomes that infect cattle in the tsetse infested and tsetse free areas of Ethiopia respectively. In the tsetse-infested areas of the country, though, the prevalence of $T$. congolense among trypanosome-infected animals was found to be high $(58.5 \%)$, a considerable number of animals were also harboring $T$. vivax infection (31.28\%) (Getachew Abebe and Yilma Jobre, 1996). Similar findings were reported by Langridge (1976) and Rowlands et al. (1995) who respectively indicated $60 \%$ T. congolonse and $31 \%$ T. vivax; and $84 \% \mathrm{~T}$. congolense and $14 \% \mathrm{~T}$. vivax infections in southwest part of Ethiopia. Higher proportions of T. congolense infection were detected in areas such as Gamo Gofa, Illubabor, Sidamo and Ghibe valley. The predominance of $T$. congolense infection in tsetse infested areas of Ethiopia indicate the existence of increased contact of cattle with tsetse vectors. This high ratio of $T$. congolense infection may also suggest that the major cyclical vectors are the savanna tsetse flies (G. m. submorsitans and G. pallidipes), which are more efficient transmitters of $T$. congolense than $T$. vivax in East Africa (Langridge, 1976). However, in areas such as Wollega and Keffa, the respective ratios between $T$. congolense and T. vivax infections were found to be more or less similar. Bourn and Scott (1978) have reported a different situation at Angar Gutin where the chief vector was G. morsitans. The study indicated a $94 \% \quad T$. vivax infection in recently introduced oxen, but on keeping the oxen on the settlement site for more than two years, the infections with $T$. vivax had dropped to less than $10 \%$. One of the factors that could depress the incidence of $T$. vivax is the use of drugs. In East Africa, except for the haemorragic syndrome, $T$. vivax is generally less virulent than $T$. congolense and consequently cattle develop tolerance to $T$. vivax more readily and easily than to $T$. congolense (Getachew Abebe and Yilma Jobre, 1996).

\section{CONCLUSION}

The present study suggests that NDVI and Tmax, when applied together, are particularly important in indicating tsetse-transmitted trypanosomosis risk areas. This is in agreement with the work of Rogers (2000) in which he highlighted that NDVI and temperature are the most important climatic variables in predicting tsetse distribution in East Africa. Previous studies on the application of GIS on African trypanosomosis were done using discriminate analysis with remotely sensed and ground-measured variables to successfully predict the presence of G. morsitans and G. pallidipes in Kenya, Tanzania and Zimbabwe (Rogers and Randolph, 1993). Results presented here indicate the importance of GDD and the two climatic variables (NDVI and Tmax) in the development of forecast model for tsetse-transmitted trypanosomosis in Ethiopia. The finding reported in this study is the first of its kind in using climate based GDD and/or CPSZ database to develop forecast models for tsetse-transmitted trypanosomosis. Furthermore, the model can be potentially used to predict tsetse abundance and trypanosomosis occurrence in other parts of Africa, where these are major concerns for development.

\section{ACKNOWLEDGMENTS}

We wish to thank the $2000 \mathrm{~J}$. William Fulbright Research Scholar Exchange Program, Council for International Exchange of Scholars (CIES) and United States Information Agency (USIA), Department of State, Washington DC for financial and administrative supports. The assistance of Mr. Michael Kearny in statistical analysis of results is highly appreciated.

\section{REFERENCES}

1. Beck, L.R., Rodrigues, M.H., Dister, S.W., Rodriguez, A.D., Washino, R.K., Roberts, D.R. and Spanner, M.A. (1994). Remote sensing as a landscape epidemiologic tool to identify villages at high risk for malaria transmission. Am. J. Trop. Hyg. 51:271-280.

2. Beck, L.R., Lobitz, B.M. and Wood, B.L. (2000). Remote sensing and human health: new sensors and new opportunities. Emerg. Inf. Dis. 6(3):217-226.

3. Bergquist, N.R. (2001). Vector-borne parasitic diseases: new trends in data collection and risk assessment. Acta Trop. 79:13-20.

4. Bourn, D. and Scott, M. (1978). The successful use of work oxen in agricultural development of tsetse infested land in Ethiopia. Trop. Anim. Hlth. Prod. 10:191-203. 
5. Bruning, J.L. and Kintz, B.C. (1977). Computational Handbook of Statistics. Glenview, IL: Scott, Foresman and Co., pp. 170-175.

6. Cross, E.R., and Bailey, C.R. (1984). Prediction of areas of endemic schistosomiasis through use of discriminate analysis of environmental data. Mil. Med. 149:542-544.

7. Cross, E.R., Newcombe, W.W. and Turker, C.J. (1996). Use of weather data and remote sensing to predict the geographic and seasonal distribution of Phlebotomus papatasi in Southwest Asia. Am. J. Trop. Hyg. 54:530-536.

8. Ephraim Mamo (1993). Trypanosomiasis. In: The Ecology of Health and Disease in Ethiopia, pp. 353-366, (Kloos, $\mathrm{H}$ and Zein, Z.A., eds). Westview Press, Boulder and Oxford.

9. Getachew Abebe and Yilma Jobre (1996). Trypanosomosis: A threat to cattle production in Ethiopia. Revue Med. Vet. 147(12): 897-902.

10. Hendrickx, G., Rocque, S., Reid, R. and Wint, W. (2001). Spatial trypanosomosis management: from data-layers to decision making. Trends Parasitol. 17(1):35-41.

11. Hugh-Jones, M.E., Barre, N., Nelson, G., Wheyness, C., Warner, J., Garris, G. and Hubbert, W. (1992). Landsat-TM identification of Amblyomma variegatum (Acari: Ixodidae) habitats in Guadeloup. Remote Sensing Environ. 40:43-55.

12. IGADD-FAO (1995). Crop Production System Zones (CPSZ) of the Inter-Governmental Authority on Drought and Development (IGADD) sub-region, Agrometeorology working paper series, No. 10, FAO, UN, Rome, Italy, 90 pp.

13. Kitron, U., Jones, C.J., Bouseman, J.K. and Baumartner, D.L. (1992). Spatial analysis of the distribution of Ixodex dammini (Acari: Ixodidae) on white-tailed deer in Ogle country, Illinois. J. Med. Entomol. 29:259-266.

14. Langridge, W.P. (1976). A tsetse and trypanosomiasis survey of Ethiopia. Ministry of Overseas Development of British and Ministry of Agriculture of Ethiopia. Addis Ababa, Ethiopia, 97 pp.

15. Lessard, P., L'Eplattenier, R.L., Norval, R.A.I., Kundert, K., Nolan, T.T., Croze, H., Walker, B., Irvin, A.D. and Perry, B.D. (1990). Geographic information system for studying the epidemiology of cattle diseases caused by Theileria parva. Vet. Rec. 89:255-262.

16. Linthicum, K.J., Bailey, C.L., Davies, G. and Tucker, C.J. (1987). Detection of rift valley fever viral activity in Kenya by satellite remote sensing imagery. Sci. 235:1656-1659.

17. Malone, J.B. and Zukowski, S.H. (1992). Geographic models and control of cattle liver flukes in southern USA. Parasitol. Today. 8:266-270.

18. Malone, J.B., Fehler, D.P., Loyacano, A.F. and Zukowski, S.H. (1992). Use of Landsat MSS imagery and soil type in a geographical information system to access site specific risk of Fasciola on Red river basin farms in Lousiana. Ann. NY. Acad. Sci. 653:389-397.

19. Malone, J.B., Abdel-Rahman, M.S., El-Bahy, M.M., Huh, O.K., Shafik, M. and Bavia, M. (1997). Geographic information systems and the distri- bution of Schistosoma mansoni in the Nile delta. Parasitol. Today. 13(3):112-119.

20. Malone, J.B., Gommes, R., Hassen, J., Yilma Jobre, Slingenberg, J., Snijder, F., Nachtergaele, F. and Ataman, E. (1998). A geographic information system on the distribution and abundance of $F$. hepatica and F. giganitica in East Africa based on Food and Agricultural Organization databases. Vet. Parasitol. 78:87-101.

21. Malone, J.B., Yilma Jobre, McCarroll, J.C., Eriko, B., Mukaratirwa, S. and Zhou, X. (2001). Satellite climatology and the environmental risk of Schistosoma mansoni in Ethiopia and East Africa. Acta Trop. 79:59-72.

22. NTTICC (2000). Annual Report. Ministry of Agriculture, National Tsetse and Trypanosomiais Investigation and Control Centre (NTTICC), Bedelle, Oromiya, Ethiopia.

23. Richards, F.O. (1993). Use of geographic information systems in control programs for onchocerciasis in Guatemala. Bull. Pan Am. Hlth. Org. 27:52-55.

24. Rogers, D.J. and Randolph, S.E. (1993). Monitoring trypanosomes in space and time. Parasitol. 106:S77-S92.

25. Rogers, D.J. (2000). Satellite, space, time and the African Trypanosomiases. Adv. Parasitol. 47:130171.

26. Rowlands, G.J., Mulatu, W., Nagda, S.M. and D'Ietreren, G.D.M. (1995). Variation in packed cell volume and trypanosome prevalence and relationship with reproductive traits in East African Zebu cows exposed to drug resistant trypanosomes. Acta Trop. 59:105-116.

27. Seifert, H.S.H. (1996). Biology and Eradication of Vectors of Animal Diseases in the Tropics. In: Tropical Animal, pp53-142, (Seifert, H.S.H., ed.) Kluwer Academic Publishers, London.

28. Thompson, D.F., Malone, J.B., Harb, H., Faris, R., Huh, O.K., Buck, A.A. and Cline, B.L. (1996). Bancroftian filariasis distribution and the diurnal temperature differences in the southern Nile delta. Emerg. Inf. Dis. 2:234-235.

29. Van Velthuizen, H., Verelst, L. and Santacroce, P. (1995). Crop Production Systems Zones (CPSZ) of IGADD sub-region. Agrometerology working paper series No. 10. FAO, Rome, Italy.

30. Yilma Jobre and Malone, J.B. (1998). A geographic information system forecast model for strategic control of fasciolosis in Ethiopia. Vet. Parasitol. 78:103-127.

31. Zeleke Dagnachew, Hailemariam Lemecha and Solomon Admasu (1985). Trypanosomiasis situation in Ethiopia. Annual Report of the Trypanosomiasis Control Service, Ministry of Agriculture.

32. Zukowski, S.H., Hill, J.M., Jones, F.W. and Malone J.B. (1991). Development and validation of a soil-based geographic information system model of habitat of Fassaria bulimoides, a snail intermediate host of Fasciola hepatica. Prev. Vet. Med. 11:221-227. 